\title{
Erratum to: From Pillars to Principles: Affirming the Field of Ecohealth
}

Pierre Horwitz

School of Natural Sciences, Edith Cowan University, Joondalup, WA 6027, Australia

\section{ERrATUM TO: EcoHealth (2012) 9:361-362 DOI $10.1007 / \mathrm{s} 10393-012-0792-4$}

In the 9.3 issue of EcoHealth the Book Review_- "From Pillars to Principles: Affirming the field of Ecohealth" by $\mathrm{P}$ Horwitz-of EcoHealth Research in Practice: Innovative Applications of an Ecosystem Approach to Health (DF Charron, ed.), two case studies from different sections of the book are referenced: "A Virtuous Cycle in the Amazon: reducing mercury exposure from fish consumption requires sustainable agriculture" and a second, a Kathmandu study, but both case studies are referenced with the same title in the Book Review. The correct title for the Kathmandu study should be "Rebuilding Urban Ecosystems for Better Community Health in Kathmandu" from "Part IV: Building Community Health into City Living" of the reviewed book.
The online version of the original article can be found under doi: 10.1007/s10393-012-0792-4.

Published online: November 16, 2012

Correspondence to: Pierre Horwitz, e-mail: p.horwitz@ecu.edu.au 